\title{
Risk of Anterior Cruciate Ligament Injury in Female Soccer Athletes: A Review
}

\author{
Sophia L. Mancini' ${ }^{1}$ Clark Dickin', Dorice A. Hankemeier ${ }^{2}$, Lindsey Rolston ${ }^{3}$, Henry Wang ${ }^{1 *}$ \\ 'Biomechanics Laboratory, Ball State University, Muncie, IN, USA \\ ${ }^{2}$ Ball State University, Muncie, IN, USA \\ ${ }^{3}$ Henry County Center for Orthopedic Surgery \& Sports Medicine, New Castle, IN, USA
}

\section{Article Info}

Article Notes

Received: March 05, 2021

Accepted: April 30, 2021

\section{${ }^{*}$ Correspondence:}

*Dr. Henry Wang, Biomechanics Laboratory, Ball State

University, Muncie, IN, USA; Email: hwang2@bsu.edu.

${ }^{\circ} 2021$ Wang $\mathrm{H}$. This article is distributed under the terms of the Creative Commons Attribution 4.0 International License.

\section{Keywords}

Anterior cruciate ligament (ACL)

$\mathrm{ACL}$ injury mechanisms

ACL injury risk

Female soccer athletes

\begin{abstract}
Soccer is becoming an increasingly popular sport amongst women. Common movements during play, such as jumping and cutting, require rapid acceleration and deceleration of multiple lower-limb joints. The anterior cruciate ligament $(A C L)$, which contributes to stabilization of the knee, is often injured during these events. ACL injury typically requires costly surgery, extended time away from sports, and jeopardizes long-term joint health. Due to sex-specific factors such as menstruation and anatomical disadvantages, women are more susceptible to tearing their ACL. Injury often occurs in non-contact scenarios during rapid acceleration or deceleration movements. Research has examined these movements and established several kinematic and kinetic mechanisms as well as muscle activation patterns that frequently occur at the time of injury, however results tend to vary based on population. This article summarizes recent and relevant literature of ACL injury mechanisms and highlights the lack of specific research in the high-risk female soccer athlete population. Due to inconclusive risk factors, injury prevention programs within this population have been inconsistent. ACL injury risk for female soccer athletes should be closer examined so that more specific injury risks can be established, and effective protective measures can be taken. Raised awareness of this need may capture attention in the research and medical communities and potentially stimulate the development of strategies that limit future $A C L$ injury and thus the challenges it brings to the high-risk female soccer athlete.
\end{abstract}

\section{Introduction}

The sport of soccer has been played both recreationally and competitively since the mid-19th century ${ }^{1}$. Over time, female participation has increased both globally and within the United States, who register 1.6 million female players, the most in the world ${ }^{2}$. With this increase, there have also been increases in injuries, one of the most notable being to the Anterior Cruciate Ligament (ACL) ${ }^{3}$. Several of soccer's most common movements such as jumping \& landing, changing directions, and sprinting ${ }^{4}$, put the athlete at risk due to their high-intensity, explosive nature. During these athletic movements, it is typical for high forces, high loading rates, and high power to act both externally and internally to the body, potentially leading to injury. Although several common musculoskeletal injuries may occur in women's soccer, the mechanisms of ACL injury for the specific population are in critical need of inspection. The purpose of this review is to provide clinicians, sports medicine professionals, strength \& conditioning professionals, etc. with recent and relevant literature regarding ACL injury risk while highlighting the lack of specific research for the high-risk female soccer athlete population. The authors hope that a better understanding of the threatening 
mechanisms this population faces will drive more specific research, and subsequently, more specified prevention programs.

\section{Literature Search}

An in-depth search was conducted to find the relevant information. Very few articles summarize the risks that the female soccer population faces, however, there are several injury risk articles related to the general population of female athlete. Articles were found via Ball State University's Library One Search journal database, allowing access to several relevant journals such as Web of Science, SPORTDiscus, ScienceDirect, PubMed, etc. All fields were searched for "history of (female* OR wom*n*) soccer", "(female* OR wom*n*) AND soccer AND injury", "Soccer AND (female* OR wom*n*) AND (Anterior cruciate ligament OR ACL)", "(female* OR wom*n*) AND soccer AND (Anterior cruciate ligament OR ACL) AND injury mechanism", "(female* OR wom*n*) AND (anterior cruciate ligament OR ACL) AND prevention", "(female* OR wom*n*) AND soccer AND injury prevention program", "(Anterior cruciate ligament OR ACL) surgery". Article acquisition began in January 2020. Searches were limited to the past 3-5 years and occasionally extended to 10 years in order to obtain a sufficient amount of the most recent literature. Bibliographies of relevant articles were cross-referenced to complete the search. During cross-referencing, some relevant articles older than 10 years were found and cited from the last 20 years, at most.

\section{History of Females in Soccer}

The first Women's World Cup took place in 1991, 61 years following the first Men's World Cup. Participation from 1991 to 2015 was assessed and indicated increases in competitiveness, potentially due to technical and tactical development across multiple countries ${ }^{5}$. Additionally, the great successes of USA, Norway and Germany reflects the nations' support for player development ${ }^{5}$. In addition to the world cup, as of 2008, FIFA also holds world championship tournaments for females registered as Under-20 and Under- $17^{6}$. As of 2019 , there were 13.36 million girls and women participating in organized soccer ${ }^{2}$.

In 1977, the first U.S. women's varsity soccer program began at Brown University. At its birth, the sport was about as widespread as fencing ${ }^{7}$, however, in 37 years the NCAA has reported 1,200\% growth (7). NCAA women's soccer ranked $2^{\text {nd }}$ as the most participated in women's collegiate sport in 2018-197. Additionally, many females from all over the world have come to the United States to participate in soccer as student-athletes. From 2014 to 2019 , international participation has increased $61 \%$ and $34 \%$ in Division I and II, respectively ${ }^{8}$. Unfortunately, as this growth of the sport continues, injury rate remains steady 9 .

\section{Common Injuries in Women's Soccer}

The rise in women's soccer injuries has been very apparent with the growth of the sport. A 15-year surveillance study (1988-89 through 2002-03) of injuries in all divisions of NCAA women's soccer noted that the 3 most common injuries in games were ankle sprains (18.3\%), knee internal derangement $(15.9 \%)$, and concussion $(8.6 \%)^{9}$. A study on top-level international players reported most injuries involving the lower extremity, also with ankle sprains as the most common diagnosis. Additionally, sprains or ligament rupture represented 96 of $387(26 \%)$ injuries reported ${ }^{10}$. An analysis of high school sports reported similar results during 1995-1997 academic years, finding $33.5 \%$ of women's soccer injuries to be of the ankle/foot and $25.8 \%$ of injuries to be hip/ thigh/leg related. Additionally, women's players sustained a higher proportion of knee surgeries than males, with 1 case of surgery per 5 team-sessions ${ }^{11}$. More recently, a study done from web-based sports injury surveillance of high school (2005-06 to 2013-14) and NCAA (2004-05 to 2013-14) women's soccer athletes found an increased injury rate in games compared to practice. Researchers predicted, based on sample size, that in these time periods $307,443(24 \%)$ concussions and 454,746 (35.5\%) ligament sprains occurred in high school and 7,826 (16.4\%) and 5,805 (31.6\%) in college, respectively. Ligament injuries were responsible for the highest rate of injuries in games ${ }^{12}$. Another study found ACL injury rate per 1000 person-days to be higher in college female players (0.391) than high school players $(0.131)^{13}$, however, data was only collected from 8 colleges and 18 high schools. In general, female college athletes were found to have the highest risk for first-time noncontact ACL injury ${ }^{13}$.

Ankle injuries are the most common type to occur in women's soccer ${ }^{14}$, with 15 years of NCAA injury surveillance data (NCAA-ISP) revealing ankle injuries account for $16.7 \%$ of all in the sport ${ }^{15}$. Hip or groin injuries are also seen often with 439 injuries occurring between 2004 and 2014, an incidence of .57 per 1000 athlete exposures ${ }^{16}$. Poor hip adductor strength as well as poor hip external rotation strength has been recognized as a predictor of noncontact ACL injury in competitive athletes ${ }^{17}$. While knee injuries might not be the most common of the lower limb, they are the leading cause of sports related surgeries ${ }^{18,19}$ and result in the most lost playing time for athletes ${ }^{15,20}$. Based on the first decade of NCAA-ISP data (2004-05 to 201314), national estimates of knee injuries in high school and college women's soccer were 259,587 (21.8\%) and 9,239 (18\%), respectively ${ }^{12}$.

\section{Burden of ACL Injury in Female Soccer Players}

1 in 19 females playing soccer rupture their $\mathrm{ACL}^{21}$, making it a well-known burden to the population. Over the 
years, there has been a significant increase in ACL surgeries done on female varsity ${ }^{15}$ and adolescent ${ }^{22}$ athletes, which could potentially exceed $\$ 650$ million annually ${ }^{23}$. Despite this, surgery is still seen as a more cost-effective option than non-operative physical therapy treatment ${ }^{24}$. The effectiveness of surgical vs. non-operative treatment regarding post-traumatic osteoarthritis ${ }^{25}$ as well as patient reported knee scores ${ }^{26}$ is still lacking. Additionally, female soccer athletes have increased rates of graft tear and contralateral ACL tear compared with similar non-soccer athletes ${ }^{27}$. This could be due to athletes not reaching baseline joint health or function before returning, and has led to suggestions of extending the typical return to play from 9-12 months to 2 years $^{28}$. Although this may be a safer option, it does not gain back lost time from sport for athletes.

Developing early-onset osteoarthritis (OA) is a debilitating long-term consequence of ACL injuries ${ }^{29}$. A follow up study done 12 years post-ACL injury on women soccer players showed $51 \%$ of subjects presented $O A$ while $82 \%$ showed signs of developing $\mathrm{OA}^{30}$. OA has also been associated with significantly poorer quality of life when compared to healthy individuals. Individuals with $\mathrm{OA}$ reported increased incidences of pain, low energy levels, poor physical mobility, poor sleep, and poor emotional reactions ${ }^{31}$. The prevalence of this injury and high stakes that it presents has led researchers to study mechanisms that may challenge the ACL's integrity as well as identify the common factors in females, however, mechanisms have not been clearly defined for specific populations.

\section{Risk Factors of ACL Injury in Female Soccer Players}

It is established in the literature that females tend to suffer from ACL injuries more frequently than their male counterparts ${ }^{4,21,32-35}$, facing a 2- to 10 -fold increased risk ${ }^{36}$. Biomechanical profile related to injury risk has manifested as early as pre-pubertal stages in females ${ }^{37}$. This is likely due not only to external movement factors such as weather, type and condition of playing surface, and footwear ${ }^{38}$, but also intrinsic factors that tend to differ between sexes.

Women tend to have a higher body mass index (BMI) than males, meaning they have more weight distributed over a given height. A higher-than-normal BMI has been associated with increased risk of injury due to potentially causing higher ground reaction forces $(\mathrm{GRF})^{39}$. Sex-specific hormones and the menstrual cycle are also theorized to affect injury risk $^{29,40}$, with some research showing increased risks in post-menarche groups ${ }^{40}$. Griffin et al., provides evidence suggesting that sex hormones cyclically increase knee laxity, which may predispose the ACL to a stretched state ${ }^{41}$. Their research also suggests that more injuries occur immediately following menstruation and just before ovulation ${ }^{41}$, however more recent literature does not support this claim. Smith et al. analyzed several studies and found them difficult to compare due to inconsistencies in defining cycle phase categorization and different measurement techniques, ultimately concluding that more research is needed in this area ${ }^{29}$. Furthermore, females are reported as predisposed due to anatomical disadvantages including decreased intercondylar femoral notch size, increased posterior slope of the tibial plateau, anterior-posterior knee laxity, and several others ${ }^{29}$.

\section{ACL Injury Mechanisms}

A non-contact ACL tear occurs when a person generates forces or moments at the knee that put the ACL under excessive loading ${ }^{42}$ while the body is not in contact with any other person or object. A contact ACL tear happens when the injury occurs due to a collision with another person or object. The ratio of non-contact to contact ACL injuries is about $7: 3^{33}$. It has been generally established that non-contact injuries have increased chances of occurring during deceleration and acceleration movements ${ }^{43}$. An in vivo study on strain behavior of the ACL reported that during rapid deceleration, the ligament elongates due to increased $\operatorname{strain}^{44}$. Literature has demonstrated that the most effective interventions for decreasing the likelihood of strain are balance training and change of direction technique modification ${ }^{45}$.

Change of direction movements that put the ACL at high risk of injury include deceleration prior to sidestepping, and landing from a jump ${ }^{33}$; two very common movements in soccer. Kinematics, kinetics, and muscle activation patterns have been analyzed to determine mechanisms that may strain the ACL and therefore increase risk of injury. These analyses can then be used to help guide prevention programs to focus on necessary strength requirements, however there are discrepancies in the literature regarding risk factors and success of prevention programs.

\section{Kinematics}

Kinematic values are closely studied to help understand the movements of a body. Motion can occur in either the frontal, sagittal or transverse plane and is respectively expressed in terms of adduction or abduction, flexion or extension, and internal or external rotation. Quantitatively, values are expressed for individual planes, however, in regards to predicting injury it has been proposed that multiplanar analysis may be the best option ${ }^{46-48}$. Quatman et al. reviewed 198 studies to determine if injuries occur solely due to mechanisms of one plane. They found that $82 \%$ of the studies examined pointed towards multiplanar conditions being more likely to cause injuries ${ }^{49}$, however, any movement that exceeds the normal physiological range of motion in any plane could potentially damage joint structures ${ }^{43,49}$. 
While multiplanar analysis may be the most beneficial method for analyzing injury risk, it is necessary to understand the mechanisms that commonly occur within each plane. Within the frontal plane, contraindications to the knee joint are described in terms of valgus or varus stresses induced by excessive outward or inward angulation of the tibia, respectively. Hewett et al. found that frontal plane analysis of valgus alignment at both initial contact and peak contact in landing are significant predictors of injury risk. In their screening of 205 female soccer, basketball, and volleyball athletes, they found a common trend of increased knee abduction angles at both contact points $\left(8.4^{\circ}\right.$ greater at initial contact and $7.6^{\circ}$ greater at peak contact) in all nine athletes who later ruptured their $\mathrm{ACL}^{47}$. Other studies dispute the effects of knee abduction on ACL injury ${ }^{50,51}$, as the medial collateral ligament (MCL) is the primary resistor of valgus moments.

Frontal plane kinematics occurring at the knee does not always occur independently of other joints. In landings with lateral trunk motion, increasing hip adduction is necessary to keep an upright stance, however, can contribute to increased knee valgus moments ${ }^{36}$. Additionally, knee valgus does not seem to occur without coupled contraindications. In 10 video cases where rupture occurred studied by Koga et al., it was revealed that both valgus and internal tibia rotation occurred almost exactly 40 milliseconds following initial ground contact ${ }^{52}$. These two movements taking place at the same time have been shown to increase strain on the ACL more than either by itself $^{53}$. Furthermore, Pollard et al. studied the relationship between frontal and sagittal plane kinematics in 58 female soccer players, finding that subjects landing with less knee flexion displayed increased average knee valgus angles of $6.3^{\circ}$ compared to $3.9^{\circ}$ in high flexion landings $(\mathrm{P}=0.02)^{54}$.

In the sagittal plane, limited hip and knee flexion have continually been seen as a risk for injury ${ }^{55-57}$. Using a stochastic biomechanical model, simulated trials with and without non-contact ACL injury were compared, and small knee flexion angle was found to be a significant risk factor for injury. Additionally, in-situ mechanical behavior of the ACL has been assessed at various knee flexion angles, finding the ACL behaved stiffer at low flexion angles and most compliant at $90^{\circ 58}$. Boden et al. conducted a 2-part comprehensive study in which 89 athletes were interviewed about the events occurring during their ACL injury and 27 video recordings of ACL injuries were reviewed. A majority of participants reported the knee position being close to full extension at the time of injury, and additionally, videotapes confirmed that most noncontact injuries occurred with the knee close to extension during a deceleration maneuver ${ }^{33}$. Fox et al. found similar sagittal plane results of limited knee flexion across the various studies reviewed ${ }^{46}$.
Range of motion in the transverse plane is fairly limited, making it difficult to assess experimentally ${ }^{49}$, however tibial internal and external rotation are important risk factors to be aware of. Miyasaka et al. studied 6 cadaveric knees and found that internal tibial rotation results in higher ACL strain than external tibial rotation ${ }^{59}$. While Quatman et al. supported this, they also suggested that external rotation has the potential to damage the ligament in weight bearing situations ${ }^{49}$, during which strain has the potential to increase by $2-4 \%$ compared to non-weight bearing instances ${ }^{60}$. Conversely, Koga et al. analyzed video of 10 injury scenarios and found valgus loading paired with internal rotation is a contributing factor to ACL injury ${ }^{52}$. Research does not specify whether internal or external rotation poses a bigger threat to the ACL, therefore analysis of more sport-specific populations and movements may be beneficial in determining risk.

\section{Kinetics}

Kinetic values, although not observable, provide information regarding the forces acting on or within the body. They are vital factors which contribute to the kinematic patterns previously discussed. GRF can be described as the equal and opposite forces applied to the body by the ground in weight bearing situations. Average GRF during landing is 4.5 body weights ${ }^{61}$ and ACL strain has been shown to peak when GRF peaks ${ }^{44,62}$. Forces acting external to the body, such as GRF, cause external moments across joint axes. Internal joint moments at the hip, knee, and ankle work to counter external moments by generating eccentric muscle actions to absorb kinetic energy during landing ${ }^{63}$. Additionally, synovial fluid within the knee joint assists in absorbing some of the compressive forces.

Higher vertical GRFs have been seen in landing with a more extended knee position ${ }^{63-65}$ and may, in part, explain the risk associated with stiff landings. In 60 centimeter drop jump landings, females demonstrated more erect posture at initial contact and the knee was found to be the primary shock absorber ${ }^{55}$, meaning that the knee joint dissipates most of the energy in this motion. Norcross et al. looked at lower extremity energy absorption in double leg jump landings. Results suggested that biomechanical factors related to injury are influenced by lower extremity energy absorption during landing, specifically with greater knee energy absorption during initial impact phase $(100$ ms after ground contact) ${ }^{66}$. In a succeeding study, it was found that during the initial impact phase, greater sagittal-plane energy absorption may indicate greater ACL loading based on increased knee-extension moments and anterior tibial shear force ${ }^{67}$. Repeatedly landing with poor mechanics during sport play can place large energy absorption demands on joints, leaving athletes at a greater risk of injury. In soccer, field players frequently jump to head the ball while goalies jump to make saves. It is 
important for players to adopt proper landing mechanics in game scenarios to avoid high impact forces.

Translation of the knee joint can occur in all 3 planes due to forces. The most common translation that occurs with landing is compression, likely as a direct result of ground reaction force and indirect result of muscle stabilization. These findings are supported by the incidence of tibial plateau bone bruises ${ }^{49}$. The tibial plateau has been assessed in vitro, showing that posterior tibial plateau slopes increased from $8.8^{\circ}$ to $13.2^{\circ}$ caused an anterior shift in the resting position of the tibia which was accentuated under axial loads ${ }^{68}$. Tibial plateau bone bruises have been assessed both in vitro ${ }^{48}$ and via magnetic resonance imaging (MRI) ${ }^{69}$ to associate bone bruise injury patterns with loading mechanisms that cause non-contact ACL injuries.

Although compression is common, it alone does not place stress on the ACL. Anterior tibial translation due to shear forces occurring at the proximal tibia is a primary ACL loading mechanism ${ }^{38,42,64,70}$. Sell et al. state that anterior tibial translation causes more direct loading than any other mechanism, with the greatest influence coming from external knee flexion moment ${ }^{62}$. Cadaver research found only knee abduction moment to significantly contribute to peak ACL strain, however, the most critical dynamic loading conditions included combinations of anterior shear force and knee abduction and internal rotation moments ${ }^{48}$. Conversely, a summary of several studies concluded that small knee flexion angle is responsible for increased anterior shear force at the knee, and thus, anterior tibial translation $^{64}$. Additionally, these authors view valgus moment as a post-injury event, stating there is no evidence that it is a primary loading mechanism.

In the sagittal plane, it was found that shear forces significantly decreased with an increase in knee flexion at landing. A 75\% increase in knee extensor moment was observed with $25-50^{\circ}$ of knee flexion and an $85 \%$ increase with $50-75^{\circ}$ of flexion ${ }^{65}$. This supports the notion that increased flexion upon landing reduces $\mathrm{GRF}^{67}$, anterior shear forces, and therefore ACL strain ${ }^{64,71-73}$. The increase seen in knee extensor moments may be associated with neuromuscular control during sport specific movements where risk factors may be present.

\section{Muscle Activation}

Both non-contractile (passive) and contractile (dynamic) mechanisms contribute to maintaining the integrity and stability of the tibiofemoral joint. The contractile mechanisms in the knee joint bring about complex relationships between the muscle-tendon units, particularly the quadriceps and hamstrings ${ }^{74}$. The quadriceps tend to have the most elevated activity upon landing ${ }^{62,75,76}$. This is because their eccentric contraction is necessary to decelerate the knee flexion that occurs upon landing ${ }^{63}$. In doing so, the quadriceps help to absorb impact forces, however, they also act as an antagonist to the ACL and consequently increase strain ${ }^{62}$. The hamstrings serve as antagonists to the quadriceps, so their activation is crucial to resist anterior tibial translation and thus ACL strain, providing stability to the knee ${ }^{77}$. The complex relationship between contractile and passive components of the knee joint is essential for safe landing and energy absorption.

Several studies have shown sex-specific differences in muscle activation ${ }^{36,72,75}$, most notably excessive quadriceps contraction paired with insufficient hamstring contraction in females ${ }^{62,75,76,78}$. It has been suggested that reduced hamstring activity relative to the quadriceps may contribute to limited knee flexion angles upon landing $42,49,65,79$ and therefore injury risk. In addition to increased hamstring contraction preventing valgus stress on the knee, gluteus maximus and medius muscles contribute by controlling the hip joint ${ }^{36}$. Training these muscles led to significantly lower peak knee abduction angles as well as greater peak knee flexion upon landing ${ }^{80}$. In the sagittal plane, increasing hamstring activation has been associated with greater knee flexion range of motion ${ }^{77,79}$ and less external rotation moments ${ }^{75}$. Furthermore, Palmieri-Smith et al. suggested that a more balanced co-contraction in the frontal plane could largely contribute to stabilization of the knee. They observed less activation in the vastus medialis compared to the vastus lateralis as well as less activation in the medial hamstrings compared to the lateral hamstrings in females ${ }^{81}$. This medial to lateral imbalance may explain why many females lack the ability to resist abduction loads in the knee joint ${ }^{75,81}$.

During landing, eccentric muscle actions of the lower extremities absorb the most kinetic energy ${ }^{66}$. Landing softly as opposed to stiffly during drop jumps causes energy absorption to spread-out over all landing phases, therefore reducing the excessive loading of the tissues. A $19 \%$ increase in muscular system absorption was seen in soft landings with the ankle plantar flexors absorbing a majority of the energy ${ }^{63}$. With a majority of energy absorption occurring at the ankle joint, this movement strategy lessens the propagation of reaction forces up the kinetic chain. This may be linked to ACL injury prevention ${ }^{65}$.

\section{Prevention Programs}

Risk factors can be modified through neuromuscular training in female athletes ${ }^{82-84}$, however, results of various studies on ACL prevention programs for soccer players are inconsistent ${ }^{64}$ Additionally, research in women's soccer reports low-level evidence that multicomponent exercisebased programs reduce ACL injuries ${ }^{85}$. Sugimoto et al. examined critical components of neuromuscular training and found age of participants, dosage of training, exercise 
variations and using verbal feedback to be predictors that optimize neuromuscular training ${ }^{86}$. Furthermore, they interpreted that ACL injury risk can be reduced by 17.2$17.7 \%$ if any of the four key components were incorporated to prevention programs ${ }^{86}$. In addition to inconsistent results, $\operatorname{cost}^{87}$ and compliance ${ }^{64,88}$ are major barriers that keep teams from participating in prevention programs.

A survey of NCAA East-Region women's soccer coaches found that most coaches are aware of prevention programs, however, feel they lack training for instructing a program $^{87}$. These athletic programs may not be financially able to either hire a position to administer training or pay to train the coaches, leading to cost being the most highly ranked barrier for non-users ${ }^{87}$. Additionally, the time consuming and labor-intensive aspects of prevention programs may limit compliance. Females who participated with low compliance faced a relative risk 4.9 times higher than those with high compliance ${ }^{88}$. A recent NCAA survey of female athletes revealed that, of the 44 soccer players that took part in the survey, 27 (61\%) were familiar with programs while only 22 (50\%) had previously participated in prevention programs ${ }^{89}$.

Some research suggests that targeting high-risk athletes can improve the efficiency of prevention programs ${ }^{86,90}$. Sugimoto et al. conducted a "numbers-needed-to-treat" analysis and found that 108 and 120 female athletes would need to be trained to prevent one non-contact or overall ACL injury, respectively, over the course of one season ${ }^{86}$. They suggest that identifying at-risk athletes may improve these numbers. A study dividing high-risk and low-risk high school female athletes found that more sport-specific techniques may be necessary for high-risk athletes to decrease ACL injury risk ${ }^{90}$. Furthermore, it has been suggested that soccer athletes prevention should include specific agility training to mimic the high risk maneuvers of the game ${ }^{91}$, however not much research has been done assessing sport-specific prevention programs within this population.

\section{Conclusion}

Lower extremity musculoskeletal injuries are a lingering threat to all female soccer athletes. The unpredictable, fast pace of the game paired with sex-specific disadvantages frequently lead to unwanted mechanics that tend to cause injury. Although this population faces several common injuries, it seems the ACL injury is one of the most detrimental in terms of need for surgery, return-toplay time, and long-term joint health. Based on current knowledge, there is a lack of understanding regarding ACL injury risk specifically in female soccer athletes, a rapidly developing population.

There appears to be a lack of population-specific research making it difficult to conclude specific kinematic, kinetic, and muscle activation patterns for female soccer athletes. The contribution of several kinematic and kinetic mechanisms as well as muscle activation patterns to ACL injury risk have not been solidified in the literature, making it difficult to apply these results to specific populations. Additionally, there is a clear need to develop more specific prevention programs for female soccer athletes, which may be able to produce positive results and potentially boost compliance.

ACL injury risk for female soccer athletes should be closer examined so that more specific injury risks can be established, and effective protective measures can be taken. Raised awareness of this need may capture attention in the research and medical communities, potentially stimulating research and thus, the development of strategies that limit future ACL injury and thus the challenges it brings to the high-risk female soccer athlete.

\section{Acknowledgement}

This project was supported by a 2021 BSU Aspire Grant. All authors declare no conflict of interest in this article.

\section{References}

1. FIFA.com. The History of Football. www.fifa.com; https://www.fifa. com/news/the-history-football-425 (2007).

2. Women's Football Member Associations Survey Report. (2019).

3. Mihata LC, Beutler AI, Boden BP. Comparing the incidence of anterior cruciate ligament injury in collegiate lacrosse, soccer, and basketball players: implications for anterior cruciate ligament mechanism and prevention. Am J Sports Med. 2006; 34(6): 899-904.

4. Arendt EA, Agel J, Dick R. Anterior Cruciate Ligament Injury Patterns Among Collegiate Men and Women. J Athl Train. 1999; 34(2): 86-92.

5. Barreira J, Da Silva CE. National teams in Women's Soccer World Cup from 1991 to 2015: participation, performance and competitiveness. Journal of Physical Education \& Sport. 2016; 16: 795-799.

6. Women's Association Football. Womens Soccer United; https://www. womenssoccerunited.com/womens-association-football/ (2010).

7. Wimmer-Schwarb A. How American Women Got a Foot in Soccer. NCAA Champion Magazine. 2019.

8. Trends in the Participation of International Student-Athletes in NCAA Divisions I and II. http://www.ncaa.org/about/resources/research/ international-student-athlete-participation. 2020.

9. Dick R, Putukian M, Agel J, et al. Descriptive epidemiology of collegiate women's soccer injuries: National Collegiate Athletic Association Injury Surveillance System, 1988-1989 through 2002-2003. J Athl Train. 2007; 42(2): 278-285.

10. Junge A, Dvorak J. Injuries in female football players in top-level international tournaments. Br J Sports Med. 2007; 41: i3-i7.

11. Powell JW, Barber-Foss KD. Injury Patterns in Selected High School Sports: A Review of the 1995-1997 Seasons. J Athl Train. 1999; 34(3): 277-284.

12. DiStefano LJ, Dann CL, Chang CJ, et al. The First Decade of Web-Based Sports Injury Surveillance: Descriptive Epidemiology of Injuries in US High School Girls' Soccer (2005-2006 Through 2013-2014) and National Collegiate Athletic Association Women's Soccer (2004-2005 Through 2013-2014). J Athl Train. 2018; 53(9): 880-892. 
13. Beynnon BD, Vacek PM, Newell MK, et al. The Effects of Level of Competition, Sport, and Sex on the Incidence of First-Time Noncontact Anterior Cruciate Ligament Injury. Am J Sports Med. 2014; 42(8): 1806-1812.

14. Gulbrandsen M, Hartigan DE, Patel KA, et al. Ten-Year Epidemiology of Ankle Injuries in Men's and Women's Collegiate Soccer Players. J Athl Train. 2019; 54(8): 881-888.

15. Hootman JM, Dick R, Agel J. Epidemiology of Collegiate Injuries for 15 Sports: Summary and Recommendations for Injury Prevention Initiatives. J Athl Train. 2007; 42(3): 311-9.

16. Ralston B, Arthur J, Makovicka JL, et al. Hip and Groin Injuries in National Collegiate Athletic Association Women's Soccer Players. Orthop J Sports Med. 2020; 8(1):2325967119892320.

17. Khayambashi K, Ghoddosi N, Straub RK, et al. Hip Muscle Strength Predicts Noncontact Anterior Cruciate Ligament Injury in Male and Female Athletes: A Prospective Study. Am J Sports Med. 2016; 44(2), 355-361.

18. Fernandez WG, Yard EE, Comstock RD. Epidemiology of Lower Extremity Injuries among U.S. High School Athletes. Acad Emerg Med. 2007; 14(7): 641-645.

19. Joseph AM, Collins CL, Henke NM, et al. A Multisport Epidemiologic Comparison of Anterior Cruciate Ligament Injuries in High School Athletics. J Athl Train. 2013; 48(6): 810-817.

20. Yang J, Tibbetts AS, Covassin T, et al. Epidemiology of Overuse and Acute Injuries Among Competitive Collegiate Athletes. J Athl Train. 2012; 47(2): 198-204.

21. Montalvo AM, Schneider DK, Yut L, et al. "What's my risk of sustaining an ACL injury while playing sports?" A systematic review with metaanalysis. Br J Sports Med. 2019; 53(16): 1003-1012.

22. Herzog MM, Marshall SW, Lund JL, et al. Incidence of Anterior Cruciate Ligament Reconstruction Among Adolescent Females in the United States, 2002 Through 2014. JAMA Pediatrics. 2017; 171(1): 808-810.

23. Hewett TE, Myer GD, Ford KR, et al. Anterior cruciate ligament injuries in female athletes: Part 1, mechanisms and risk factors. Am J Sports Med. 2006; 34(2): 299-311.

24. Stewart BA, Momaya AM, Silverstein MD, et al. The Cost-Effectiveness of Anterior Cruciate Ligament Reconstruction in Competitive Athletes. Am J Sports Med. 2017; 45(1): 23-33.

25. Wang LJ, Zeng N, Yan ZP, et al. Post-traumatic osteoarthritis following ACL injury. Arthritis Research \& Therapy. 2020; 22: 57.

26. Monk AP, Davies LJ, Hopewell S, et al. Surgical versus conservative interventions for treating anterior cruciate ligament injuries. Cochrane Database Syst Rev. 2016; 4(4): CD011166.

27. Allen MM, Pareek A, Krych AJ, et al. Are Female Soccer Players at an Increased Risk of Second Anterior Cruciate Ligament Injury Compared With Their Athletic Peers? Am J Sports Med. 2016; 44(10): 2492-2498.

28. Nagelli CV, Hewett TE. Should Return to Sport be Delayed Until 2 Years After Anterior Cruciate Ligament Reconstruction? Biological and Functional Considerations. Sports Med. 2017; 47(2): 221-232.

29. Smith HC, Vacek P, Johnson RJ, et al. Risk Factors for Anterior Cruciate Ligament Injury: Part 1. Sports Health. 2012; 4(1): 69-78.

30. Lohmander LS, Englund PM, Dahl LL, et al. The long-term consequence of anterior cruciate ligament and meniscus injuries: Osteoarthritis. The American Journal of Sports Medicine. 2007; 35(10): 1756-69.

31. Yildiz N, Topuz O, Gungen GO, et al. Health-related quality of life (Nottingham Health Profile) in knee osteoarthritis: correlation with clinical variables and self-reported disability. Rheumatol Int. 2010; 30(12): 1595-1600.
32. Agel J, Arendt EA, Bershadsky B. Anterior cruciate ligament injury in National Collegiate Athletic Association basketball and soccer: a 13year review. The American Journal of Sports Medicine. 2005; 33(4): 524-530.

33. Boden BP, Dean GS, Feagin JA Jr, et al. Mechanisms of anterior cruciate ligament injury. Orthopedics. 2000; 23(6): 573-578.

34. Ford KR, Myer GD, Smith RL, et al. A comparison of dynamic coronal plane excursion between matched male and female athletes when performing single leg landings. Clin Biomech (Bristol, Avon). 2006; 21(1): 33-40.

35. Renstrom P, Ljungqvist A, Arendt E, et al. Non-contact ACL injuries in female athletes: an International Olympic Committee current concepts statement. British Journal of Sports Medicine. 2008; 42: 394-412.

36. Hewett TE, Myer GD. The Mechanistic Connection Between the Trunk, Knee, and Anterior Cruciate Ligament Injury. Exerc Sport Sci Rev. 2011; 39(4): 161-166.

37. Sigward SM, Pollard CD, Powers CM. The influence of sex and maturation on landing biomechanics: implications for anterior cruciate ligament injury. Scand J Med Sci Sports. 2012; 22(4): 502509.

38. Smith HC, Vacek P, Johnson RJ, et al. Risk Factors for Anterior Cruciate Ligament Injury: Part 2. Sports Health. 2012; 4(2): 155-161.

39. Uhorchak JM, Scoville CR, Williams GN, et al. Risk factors associated with noncontact injury of the anterior cruciate ligament - A prospective four-year evaluation of 859 West Point cadets. Am J Sports Med. 2003; 31(6): 831-42.

40. Kim KW, Lim BO. Effects of menarcheal age on the anterior cruciate ligament injury risk factors during single-legged drop landing in female artistic elite gymnasts. Arch Orthop Trauma Surg. 2014; 134(11): 1565-1571.

41. Griffin LY, Albohm MJ, Arendt EA, et al. Understanding and preventing noncontact anterior cruciate ligament injuries: a review of the Hunt Valley II meeting, January 2005. Am J Sports Med. 2006; 34(9): 151232.

42. Yu B, Garrett WE. Mechanisms of non-contact ACL injuries. Br J Sports Med. 2007; 41: i47-i51.

43. Shimokochi Y, Shultz SJ. Mechanisms of Noncontact Anterior Cruciate Ligament Injury. Journal of Athletic Training. 2008; 43(4): 396-408.

44. Cerulli G, Benoit DL, Lamontagne M, et al. In vivo anterior cruciate ligament strain behaviour during a rapid deceleration movement: case report. Knee Surg Sports Traumatol Arthrosc. 2003; 11(5): 307311.

45. Dos'Santos T, Thomas C, Comfort P, et al. The Effect of Training Interventions on Change of Direction Biomechanics Associated with Increased Anterior Cruciate Ligament Loading: A Scoping Review. Sports Med. 2019; 49(12): 1837-1859. doi:10.1007/s40279-01901171-0

46. Fox AS, Bonacci J, McLean SG, et al. What is Normal? Female Lower Limb Kinematic Profiles During Athletic Tasks Used to Examine Anterior Cruciate Ligament Injury Risk: A Systematic Review. Sports Medicine. 2014; 44(6): 815-32.

47. Hewett TE, Myer GD, Ford KR, et al. Biomechanical measures of neuromuscular control and valgus loading of the knee predict anterior cruciate ligament injury risk in female athletes: a prospective study. Am J Sports Med. 2005; 33(4): 492-501.

48. Levine JW, Kiapour AM, Quatman CE, et al. Clinically Relevant Injury Patterns After an Anterior Cruciate Ligament Injury Provide Insight Into Injury Mechanisms. Am J Sports Med. 2013; 41(2): 385-395. 
49. Quatman CE, Quatman-Yates CC, Hewett TE. A 'plane' explanation of anterior cruciate ligament injury mechanisms: a systematic review. Sports Medicine. 2010; 40(9): 729-46.

50. Mazzocca AD, Nissen CW, Geary M, et al. Valgus medial collateral ligament rupture causes concomitant loading and damage of the anterior cruciate ligament. J Knee Surg. 2003; 16(3): 148-151.

51. Shin CS, Chaudhari AM, Andriacchi TP. The effect of isolated valgus moments on ACL strain during single-leg landing: A simulation study. Journal of Biomechanics. 2009; 42(3): 280-285.

52. Koga H, Nakamae A, Shima Y, et al. Mechanisms for noncontact anterior cruciate ligament injuries: knee joint kinematics in 10 injury situations from female team handball and basketball. Am J Sports Med. 2010; 38(11): 2218-2225.

53. Shin CS, Chaudhari AM, Andriacchi TP. Valgus Plus Internal Rotation Moments Increase Anterior Cruciate Ligament Strain More Than Either Alone. Med Sci Sports Exerc. 2011; 43(8): 1484-91.

54. Pollard CD, Sigward SM, Powers CM. Limited hip and knee flexion during landing is associated with increased frontal plane knee motion and moments. Clin Biomech (Bristol, Avon). 2010; 25(2): 142-6.

55. Decker MJ, Torry MR, Wyland DJ, et al. Gender differences in lower extremity kinematics, kinetics and energy absorption during landing. Clin Biomech (Bristol, Avon). 2003; 18(7): 662-9.

56. Leppänen M, Pasanen K, Krosshaug T, et al. Sagittal Plane Hip, Knee, and Ankle Biomechanics and the Risk of Anterior Cruciate Ligament Injury: A Prospective Study. Orthop J Sports Med. 2017; 5(12): 2325967117745487.

57. Lin CF, Liu H, Gros MT, et al. Biomechanical risk factors of non-contact ACL injuries: A stochastic biomechanical modeling study. Journal of Sport and Health Science. 2012; 1(1): 36-42.

58. Rachmat HH, Janssen DW, Verkerke GJ, et al. In-situ mechanical behavior and slackness of the anterior cruciate ligament at multiple knee flexion angles. Medical Engineering \& Physics. 2016; 38: 209215.

59. Miyasaka T, Matsumoto $\mathrm{H}$, Suda $\mathrm{Y}$, et al. Coordination of the anterior and posterior cruciate ligaments in constraining the varus-valgus and internal-external rotatory instability of the knee. Journal of Orthopaedic Science. 2002; 7(3): 348-53.

60. Fleming BC, Renstrom PA, Beynnon BD, et al. The effect of weightbearing and external loading on anterior cruciate ligament strain. J Biomech. 2001; 34(2): 163-170.

61. McNair PJ, Prapavessis H. Normative data of vertical ground reaction forces during landing from a jump. J Sci Med Sport. 1999; 2(1): 86-88.

62. Sell TC, Ferris CM, Abt JP, et al. Predictors of proximal tibia anterior shear force during a vertical stop-jump. Journal of Orthopaedic Research. 2007; 25(12): 1589-1597.

63. Devita P, Skelly WA. Effect of landing stiffness on joint kinetics and energetics in the lower extremity. Med Sci Sports Exerc. 1992; 24(1): 108-115.

64. Dai B, Mao D, Garrett WE, et al. Anterior cruciate ligament injuries in soccer: Loading mechanisms, risk factors, and prevention programs. Journal of Sport and Health Science. 2014; 3: 299-306.

65. Podraza JT, White SC. Effect of knee flexion angle on ground reaction forces, knee moments and muscle co-contraction during an impactlike deceleration landing: Implications for the non-contact mechanism of ACL injury. Knee. 2010; 17(4): 291-5.

66. Norcross MF, Lewek MD, Padua DA, et al. Lower Extremity Energy Absorption and Biomechanics During Landing, Part I: Sagittal-Plane Energy Absorption Analyses. J Athl Train. 2013; 48(6): 748-756.

67. Norcross MF, Lewek MD, Padua DA, et al. Lower Extremity Energy Absorption and Biomechanics During Landing, Part II: Frontal-Plane
Energy Analyses and Interplanar Relationships. J Athl Train. 2013; 48(6): 757-763.

68. Giffin JR, Vogrin TM, Zantop T, et al. Effects of increasing tibial slope on the biomechanics of the knee. Am J Sports Med. 2004; 32(2): 376382.

69. Kim SY, Spritzer CE, Utturkar GM, et al. Knee Kinematics During Noncontact ACL Injury as Determined from Bone Bruise Location. Am J Sports Med. 2015; 43(10): 2515-2521.

70. DeMorat G, Weinhold P, Blackburn T, et al. Aggressive quadriceps loading can induce noncontact anterior cruciate ligament injury. Am J Sports Med. 2004; 32(2): 477-483.

71. Chappell JD, Yu B, Kirkendall DT, et al. A comparison of knee kinetics between male and female recreational athletes in stop-jump tasks. Am J Sports Med. 2002; 30(2): 261-267.

72. Chappell JD, Creighton RA, Giuliani C, et al. Kinematics and electromyography of landing preparation in vertical stop-jump: risks for noncontact anterior cruciate ligament injury. Am J Sports Med. 2007; 35(2): 235-241.

73. Taylor KA, Terry ME, Utturkar GM, et al. Measurement of in vivo anterior cruciate ligament strain during dynamic jump landing. J Biomech. 2011; 44(3): 365-371.

74. Hughes G, Watkins J. A Risk-Factor Model for Anterior Cruciate Ligament Injury. Sports Med. 2006; 36(5): 411-428.

75. Bencke J, Aagaard P, Zebis MK. Muscle Activation During ACL Injury Risk Movements in Young Female Athletes: A Narrative Review. Front Physiol. 2018; 9: 445.

76. Shultz SJ, Nguyen AD, Leonard MD, et al. Thigh Strength and Activation as Predictors of Knee Biomechanics During a Drop Jump Task. Med Sci Sports Exerc. 2009; 41(4): 857-866.

77. Blackburn JT, Norcross MF, Cannon LN, et al. Hamstrings Stiffness and Landing Biomechanics Linked to Anterior Cruciate Ligament Loading. J Athl Train. 2013; 48(6): 764-772.

78. Tsai LC, Ko YA, Hammond KE, et al. Increasing hip and knee flexion during a drop-jump task reduces tibiofemoral shear and compressive forces: implications for ACL injury prevention training. J Sports Sci. 2017; 35(24): 2405-2411.

79. Walsh M, Boling MC, McGrath M, et al. Lower Extremity Muscle Activation and Knee Flexion During a Jump-Landing Task. J Athl Train. 2012; 47(4): 406-413.

80. Stearns KM, Powers CM. Improvements in hip muscle performance result in increased use of the hip extensors and abductors during a landing task. Am J Sports Med. 2014; 42(3): 602-609.

81. Palmieri-Smith RM, McLean SG, Ashton-Miller JA, et al. Association of Quadriceps and Hamstrings Cocontraction Patterns With Knee Joint Loading. Journal of Athletic Training. 2009; 44(3), 256-263.

82. Chappell JD, Limpisvasti 0. Effect of a Neuromuscular Training Program on the Kinetics and Kinematics of Jumping Tasks. Am J Sports Med. 2008; 36(6): 1081-1086.

83. Lephart SM, Abt JP, Ferris CM, et al. Neuromuscular and biomechanical characteristic changes in high school athletes: a plyometric versus basic resistance program. British Journal of Sports Medicine. 2005; 39(12): 932-938.

84. Paterno MV, Myer GD, Ford KR, et al. Neuromuscular training improves single-limb stability in young female athletes. J Orthop Sports Phys Ther. 2004; 34(6): 305-316.

85. Crossley KM, Patterson BE, Culvenor AG, et al. Making football safer for women: a systematic review and meta-analysis of injury prevention programmes in 11773 female football (soccer) players. Br J Sports Med. 2020; 54: 1089-1098. 
86. Sugimoto D, Myer GD, McKeon JM, et al. Evaluation of the effectiveness of neuromuscular training to reduce anterior cruciate ligament injury in female athletes: a critical review of relative risk reduction and numbersneeded-to-treat analyses. Br J Sports Med. 2012; 46(14): 979-988.

87. Dix C, Logerstedt D, Arundale A, et al. Perceived barriers to implementation of injury prevention programs among collegiate women's soccer coaches. Journal of Science and Medicine in Sport. 2021; 24(4): 352-356.

88. Sugimoto D, Myer GD, Bush HM, et al. Compliance With Neuromuscular Training and Anterior Cruciate Ligament Injury Risk Reduction in Female Athletes: A Meta-Analysis. J Athl Train. 2012; 47(6): 714-723.
89. Tanaka MJ, Jones LC, Forman JM. Awareness of Anterior Cruciate Ligament Injury-Preventive Training Programs Among Female Collegiate Athletes. J Athl Train. 2020; 55(4): 359-364.

90. Myer GD, Ford KR, Brent JL, et al. Differential neuromuscular training effects onACL injury risk factors in"high-risk" versus 'low-risk' athletes. BMC Musculoskelet Disord. 2007; 8: 39.

91. Michaelidis M, Koumantakis GA. Effects of knee injury primary prevention programs on anterior cruciate ligament injury rates in female athletes in different sports: a systematic review. Phys Ther Sport. 2014; 15(3): 200-210. 